\title{
Origin of the ${ }^{2} E \leftrightarrow{ }^{4} T_{2}$ Fano resonance in $\mathrm{Cr}^{3+}$-doped $\mathrm{LiCaAlF}_{6}$ : Pressure-induced excited-state crossover
}

\author{
M. N. Sanz-Ortiz, ${ }^{1}$ F. Rodríguez, ${ }^{1, *}$ I. Hernández, ${ }^{1}$ R. Valiente, ${ }^{2}$ and S. Kück ${ }^{3}$ \\ ${ }^{1}$ MALTA Consolider Team, DCITIMAC, Facultad de Ciencias, University of Cantabria, 39005 Santander, Spain \\ ${ }^{2}$ MALTA Consolider Team, Depto. Física Aplicada, Facultad de Ciencias, University of Cantabria, 39005 Santander, Spain \\ ${ }^{3}$ Physikalisch-Technische Bundesanstalt, Bundesallee 100, 38116 Braunschweig, Germany
}

(Received 6 October 2009; revised manuscript received 13 November 2009; published 12 January 2010)

\begin{abstract}
This work investigates pressure-induced phase transition (PT) and excited-state-crossover effects on the photoluminescence (PL) properties of $\mathrm{LiCaAlF}_{6}: \mathrm{Cr}^{3+}$. We report a PL study by means of time-resolved emission, excitation, and lifetime measurements as a function of pressure. We focus on $\mathrm{Cr}^{3+} \mathrm{PL}$ variations around pressure-induced trigonal-to-monoclinic first-order $\mathrm{PT}$ in $\mathrm{LiCaAlF}_{6}$ at $7 \mathrm{GPa}$. Moreover, the structural requirements for changing $\mathrm{Cr}^{3+} \mathrm{PL}$ from a broadband emission at $1.59 \mathrm{eV}(781 \mathrm{~nm})$ at ambient conditions, to a rubylike narrow-line emission at $1.87 \mathrm{eV}(663 \mathrm{~nm})$ are analyzed in the $0-35 \mathrm{GPa}$ range. We show how pressure progressively transforms $\mathrm{Cr}^{3+}$ broadband PL into a rubylike emission that becomes the dominant feature of the room-temperature emission spectrum at $28 \mathrm{GPa}$. This behavior, together with the pressure dependences of the ${ }^{2} E$ and ${ }^{4} T_{2}$ excited-states energy and PL lifetime, are explained on the basis of the electron-phonon coupling associated with the ${ }^{4} T_{2}$ and ${ }^{2} E$ states. We demonstrate that both excited states interact through spin-orbit coupling yielding Fano resonance rather than antiresonance as is frequently assumed.
\end{abstract}

DOI: 10.1103/PhysRevB.81.045114

\section{INTRODUCTION}

Pressure-induced excited-state crossover (ESCO) in $\mathrm{Cr}^{3+}$-doped materials is a rather intriguing phenomenon that has motivated spectroscopists to find out new ways to modify and control photoluminescence (PL) properties in $\mathrm{Cr}^{3+}$-based materials. ESCO has also been efficiently used to identify different $\mathrm{Cr}^{3+}$ centers formed in $\mathrm{Cr}^{3+}$-doped crystals. ${ }^{1-5}$ Besides their applications as tunable solid-state lasers and PL materials, ${ }^{6-8}$ fluoroelpasolites,,${ }^{1,9}$ garnets,,${ }^{1-4,10}$ and niobates, ${ }^{5,11,12}$ are attractive host materials for $\mathrm{Cr}^{3+}$ to investigate ESCO processes since they provide crystal fields (CF) around $\mathrm{Cr}^{3+}$ close to the ${ }^{2} E \leftrightarrow{ }^{4} T_{2}$ crossing point. In fluorides, $\mathrm{LiCaAlF}_{6}: \mathrm{Cr}^{3+}$ provides the highest $\mathrm{CF}$ at the $\mathrm{Al}^{3+}$ site for investigating ESCO phenomena. ${ }^{6-9,13}$ Each excited state exhibits a rather different PL due to the different electron-lattice coupling. The spin-allowed ${ }^{4} T_{2} \rightarrow{ }^{4} A_{2}\left(t_{2}^{2} e^{1}\right.$ $\left.\rightarrow t_{2}^{3} e^{0}\right)$ transition [Fig. 1(a)], whose energy corresponds to the CF splitting, $\Delta$, is strongly coupled to the lattice providing short-lived broadband PL. Nevertheless the spinforbidden ${ }^{2} E \rightarrow{ }^{4} A_{2}$ transition does not involve any change in electronic configuration (spin flip $t_{2}^{3} e^{0}$ ) and is therefore weakly coupled to the lattice, giving rise to long-lived narrow-line emission ( $R$ lines). The PL-excited state of $\mathrm{Cr}^{3+}$ in fluorides at ambient pressure lies below the ESCO leading to a ${ }^{4} T_{2} \rightarrow{ }^{4} A_{2}$ broadband emission. ${ }^{6-9,14-28}$ Pressure increases $\Delta$ toward the ESCO providing ideal conditions for drastic PL transformations (Fig. 1).

The pressure effect is expected to be particularly important in $\mathrm{LiCaAlF}_{6}: \mathrm{Cr}^{3+}$ since the host material exhibits a firstorder phase transition (PT) from the trigonal $P \overline{3} 1 c$ (phase I) to monoclinic $P 2_{1} / c$ (phase II) between 7 and $9 \mathrm{GPa}$, which reduces $\mathrm{Cr}^{3+}$ site symmetry. ${ }^{13}$ In this work we investigate the effects of pressure-induced PT and the ${ }^{4} T_{2} \leftrightarrow{ }^{2} E$ ESCO on the PL properties of $\mathrm{LiCaAlF}_{6}: \mathrm{Cr}^{3+}$. One aim is to induce variations in the $\mathrm{Cr}^{3+} \mathrm{PL}$ by reducing the $\left(\mathrm{CrF}_{6}\right)^{3-}$ complex volume through structural changes along the $\mathrm{PT}$ and explore
PACS number(s): 71.70. $-\mathrm{d}, 61.50 . \mathrm{Ks}, 71.55 .-\mathrm{i}, 78.55 .-\mathrm{m}$

whether the associated pressure hysteresis is able to stabilize phase II at ambient conditions.

Although $\mathrm{Cr}^{3+} \mathrm{ESCO}$ was first observed by Dolan et al., ${ }^{1}$ in $\mathrm{K}_{2} \mathrm{NaGaF}_{6}: \mathrm{Cr}^{3+}$ at $6.1 \mathrm{GPa}$ and $154 \mathrm{~K}$, later by Freire $e t$ al. ${ }^{23}$ in $\mathrm{KZnF}_{3}: \mathrm{Cr}^{3+}$ and recently by Hernández et al. ${ }^{9}$ in $\mathrm{Rb}_{2} \mathrm{KCrF}_{6}$, the PL change toward a complete rubylike emission $\left({ }^{2} E \rightarrow{ }^{4} A_{2}\right)$ has never been observed at room temperature (RT) in fluorides. This is due to the high-pressure con- (a)

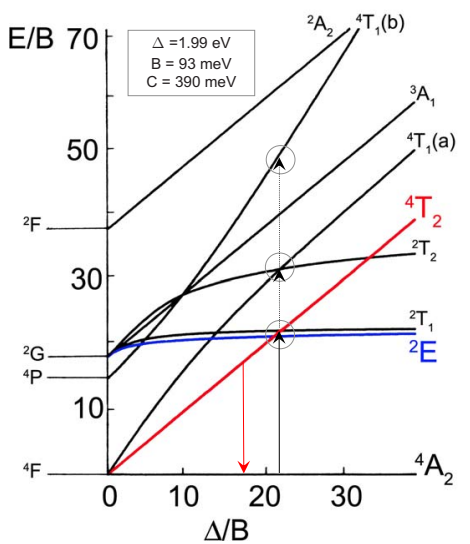

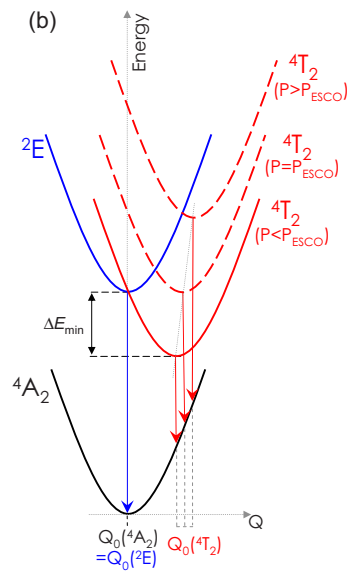

FIG. 1. (Color online) (a) Tanabe-Sugano energy-level diagram corresponding to the $3 d^{3}$ electronic configuration of $\mathrm{Cr}^{3+}$ in octahedral symmetry. The arrows indicate the crystal-field transitions observed in the room-temperature optical-absorption spectrum of $\mathrm{LiCaAlF}_{6}: \mathrm{Cr}^{3+}$. The energies in units of the Racah parameter $B$ (circles in the Tanabe-Sugano diagram) correspond to $B=93 \mathrm{meV}$ $\left(750 \mathrm{~cm}^{-1}\right), \quad C=390 \mathrm{meV} \quad\left(3100 \mathrm{~cm}^{-1}\right), \quad$ and $\Delta=1.99 \mathrm{eV}$ $\left(16080 \mathrm{~cm}^{-1}\right): C / B=4.2$ and $\Delta / B=21.4 \quad\left([\Delta / B]_{\mathrm{ESCO}}=22\right)$. (b) Single-coordinate configurational curves for the ${ }^{4} T_{2}$ and ${ }^{2} E$ emitting excited states and the ${ }^{4} A_{2}$ ground state at different pressures below (solid lines) and above (dotted lines) the excited-state crossover pressure, $P_{\mathrm{ESCO}}$. The relevant spectroscopic parameters for describing ESCO are indicated. 
ditions required to place the emitting state ${ }^{4} T_{2}$ (broadband PL) far above the ${ }^{2} E$ emitting state (narrow-line PL) in order to get ${ }^{2} E$ mostly populated at RT. As we will see in this paper, an energy separation above $0.2 \mathrm{eV}\left(\Delta E \approx 8 \mathrm{k}_{B} T\right)$ would enable the long-lived ${ }^{2} E \rightarrow{ }^{4} A_{2}$ transition $(\tau=2.7 \mathrm{~ms})$ to be the major contribution to the $\mathrm{LiCaAlF}_{6}: \mathrm{Cr}^{3+} \mathrm{PL}$ spectrum (R1 and R2 lines), beyond the short-lived ${ }^{4} T_{2} \rightarrow{ }^{4} A_{2}$ transition, $\tau=170 \mu$ s in phase I at ambient conditions $(\tau=70 \mu \mathrm{s}$ in phase II). It is worth noting that this energy is the difference between excited-state configuration minima $\Delta E_{\min }=E_{\min }\left({ }^{4} T_{2}\right)-E_{\min }\left({ }^{2} E\right)$ [Fig. 1(b)] and not the one obtained for the ground-state equilibrium configuration of $\left(\mathrm{CrF}_{6}\right)^{-3}$ given by the Tanabe-Sugano (TS) diagram [Fig. 1(a)]. Therefore, ESCO implies crossing of zero-phonon lines ${ }^{4} T_{2} \leftrightarrow{ }^{2} E$ in terms of spectroscopic parameters; i.e., the emitting excited state for the ${ }^{4} A_{2}$ ground-state configuration corresponds to the high spin ${ }^{4} T_{2}$ although the excited-state energies associated with the ${ }^{4} T_{2}$ and ${ }^{2} E$ are identical [Fig. 1(b)]. Actually, the first absorption band for this system exhibits Fano resonance reflecting the energy closeness of the ${ }^{4} T_{2},{ }^{2} E$, and ${ }^{2} T_{1}$ excited states. The knowledge of the linear and quadratic electron-phonon coupling for the PL excited states is essential to draw the configurational energy diagrams for predicting ESCO phenomena. Furthermore the origin of the Fano resonance associated with ${ }^{4} T_{2} \leftrightarrow{ }^{2} E$ is investigated through optical spectroscopy under pressure, which unraveled very useful to determine the zerophonon line (ZPL) energy between ${ }^{4} A_{2} \leftrightarrow{ }^{2} E$ even if it cannot be detected at ambient conditions. ${ }^{9}$ We show that pressureinduced ESCO is attained at $6 \mathrm{GPa}$ at RT. However this pressure corresponds to the crossover of the excited-state configuration-energy minima of the ${ }^{4} T_{2}$ and ${ }^{2} E$ states: $E_{\text {min }}\left({ }^{4} T_{2}\right)>E_{\text {min }}\left({ }^{2} E\right)$, is not able to transform the broadband PL to a narrow-line emission at RT since radiative deexcitation mainly takes place from the short-lived ${ }^{4} T_{2}$ state.

In this work we investigate whether ESCO can be detected by spectroscopy through the ${ }^{4} T_{2}$ and ${ }^{2} E$ ZPL energies and the minimum pressure required to get narrow-line emission at RT. In addition, the knowledge of the ${ }^{2} E$ ZPL position is crucial to reveal the origin of the ${ }^{4} T_{2} \leftrightarrow{ }^{2} E$ resonance as a Fano resonance or an anti-Fano resonance, a feature which has been controversial in $\mathrm{Cr}^{3+}$-doped oxides and fluorides. ${ }^{29-32}$

\section{EXPERIMENT}

The microcrystals used in pressure experiments $(70 \times 50$ $\times 15 \mu^{3}$ ) were obtained by cleavage from a $\mathrm{LiCaAlF}_{6}: \mathrm{Cr}^{3+}(2 \mathrm{~mol} \%)$ single-crystal rod. Time-resolved emission and excitation spectra and PL time-dependent measurements were performed in the $0-35 \mathrm{GPa}$ pressure range using the experimental setup described elsewhere. ${ }^{33,34}$ These spectra were attained exciting the sample with a Vibrant B355II OPO pulsed laser operating in the 410-2400 nm range. The $407 \mathrm{~nm}$ line of a Coherent I-302 $\mathrm{Kr}^{+}$laser was used for obtaining emission spectra under $\mathrm{cw}$ excitation. The PL intensity was dispersed by a Chromex 500IS monochromator and detected by photon-counting techniques using a SR400 photon counter measuring photocurrent pulses of

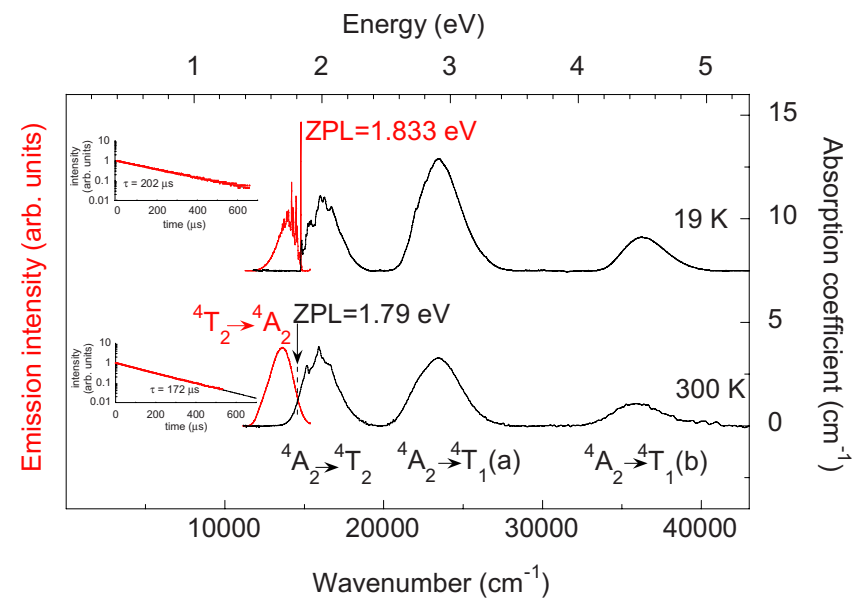

FIG. 2. (Color online) Optical absorption and corresponding emission (excitation wavelength, $\lambda_{\mathrm{exc}}=633 \mathrm{~nm}$ ) spectra of $\mathrm{LiCaAlF}_{6}: \mathrm{Cr}^{3+}(2 \%)$ single crystal at 19 and $300 \mathrm{~K}$ (phase I). The time-dependence emission decay at each temperature with the corresponding fitted lifetime is given as an inset. Note the presence of Fano resonance in the first ${ }^{4} A_{2} \rightarrow{ }^{4} T_{2}$ absorption band around 1.99 eV.

$500 \mu$ s after the laser pulse for 50 averages. Time-resolved emission spectra were corrected for instrumental response using a calibrated tungsten lamp. The PL signal for timeresolved excitation spectroscopy was measured at the band maximum varying the laser wavelength in the $410-730 \mathrm{~nm}$ range and was normalized to the pulse intensity averaged for 200 pulses. All the spectra were corrected for wavelength dependence instrumental response. The PL decay curves $I(t)$ for lifetime measurements under pressure were obtained through a Tektronix 2430A scope. All the experimental curves $I_{\exp }(t)$ exhibited a single exponential behavior in the explored pressure range and were fitted to a function $I_{\exp }(t)$ $=I_{\text {back }}+I_{0} \exp (-t / \tau)$ where the background intensity, $I_{\text {back }}$, was directly measured from $I_{\exp }(t)$ for times before the excitation pulse $(t<0)$.

Absorption spectra were obtained with a Perkin-Elmer Lambda 9 spectrophotometer. The low-temperature absorption and emission spectra were obtained with a closed cycle He Scientific Instruments 202 cryostat with an APD-K temperature controller. High-pressure experiments in the 0-35 $\mathrm{GPa}$ range were performed in a diamond anvil cell, High Pressure Diamond Optics, Inc. using silicone oil (DowCorning 200 fluid 300000 cst) as pressure transmitter. Pressure was calibrated through the ruby $R$-line shift. The pressure and hydrostatic conditions within the cavity at high pressure were explored by three different ruby chips nearby the sample. In addition, we have checked in situ the $\mathrm{LiCaAlF}_{6}: \mathrm{Cr}^{3+}$ through its $R$-line position and broadening, respectively. $\mathrm{Up}$ to $35 \mathrm{GPa}$, hydrostaticity is fairly good with estimated nonhydrostatic pressures smaller than $3 \%$.

\section{RESULTS AND DISCUSSION}

\section{A. Absorption and emission spectra at ambient pressure}

Figure 2 shows ambient pressure 19 and $300 \mathrm{~K}$ optical 
TABLE I. $\mathrm{LiCaAlF}_{6}: \mathrm{Cr}^{3+}$ emission and absorption energies and Racah and $\mathrm{CF}$ parameters at 19 and 297 K.

\begin{tabular}{|c|c|c|c|c|c|c|c|c|}
\hline \multirow{2}{*}{$\begin{array}{c}\text { Temperature } \\
(\mathrm{K})\end{array}$} & \multirow{2}{*}{$\begin{array}{c}\text { Emission } \\
(\mathrm{eV})^{4} T_{2} \rightarrow{ }^{4} A_{2}\end{array}$} & \multicolumn{4}{|c|}{$\begin{array}{l}\text { Absorption } \\
(\mathrm{eV}){ }^{4} A_{2} \rightarrow\end{array}$} & \multirow{2}{*}{$\begin{array}{c}B \\
(\mathrm{eV})\end{array}$} & \multirow{2}{*}{$\begin{array}{c}\Delta \\
(\mathrm{eV})\end{array}$} & \multirow[b]{2}{*}{$C / B$} \\
\hline & & ${ }^{4} T_{2}(F)$ & ${ }^{4} E(G)$ & ${ }^{4} T_{1}(F)$ & ${ }^{4} T_{1}(P)$ & & & \\
\hline 297 & 1.69 & 1.99 & (1.88) & 2.90 & 4.48 & 0.093 & 1.99 & 4.2 \\
\hline 19 & 1.71 & 2.03 & (1.88) & 2.91 & 4.50 & 0.093 & 2.03 & \\
\hline
\end{tabular}

absorption (OA) and PL spectra and the associated PL time dependence: 202 and $172 \mu$ s, respectively. This lifetime decrease with increasing temperature and the increase in the transition-oscillator strength are activated by the odd-parity vibration mechanism characteristic of $d$ - $d$ transitions in centrosymmetric systems such as $\left(\mathrm{CrF}_{6}\right)^{3-}$ in $\mathrm{LiCaAlF}_{6}: \mathrm{Cr}^{3+}$ (Refs. 6 and 35). The appearance of the narrow features in the low-temperature absorption and emission spectra states is noteworthy. They are due to electronic transitions between vibronic states and thus provide the vibrational structure of the coupled modes for the excited (absorption) and the ground (emission) states. ${ }^{36}$ An account for the vibronic structure of $\mathrm{Cr}^{3+}$ electronic spectra is given elsewhere. $9,14,16,19,27$

The OA spectrum consists of three broadbands, located at $1.99,2.90$, and $4.48 \mathrm{eV}$ that correspond within $\left(\mathrm{CrF}_{6}\right)^{3-}$ to ${ }^{4} A_{2} \rightarrow{ }^{4} T_{2} \quad\left({ }^{2} E\right.$ and $\left.{ }^{2} T_{1}\right),{ }^{4} A_{2} \rightarrow{ }^{4} T_{1}(a)$, and ${ }^{4} A_{2} \rightarrow{ }^{4} T_{1}(b)$ crystal-field (CF) transitions of $\mathrm{Cr}^{3+}$, respectively [Figs. 1(a) and 2]. The associated Racah and $\mathrm{CF}$ parameters obtained by fitting the $300 \mathrm{~K} \mathrm{OA}$ spectrum (Fig. 2) are; ${ }^{37} B=93 \mathrm{meV}$; $C=390 \mathrm{meV}(C / B=4.2)$; and $\Delta=1.99 \mathrm{eV}(\Delta / B=21)$ [Fig. 1(a)]. The corresponding emission spectrum, obtained under excitation in any of the three OA bands, consists of a broadband located at $1.69 \mathrm{eV}(734 \mathrm{~nm})$ at RT and $1.74 \mathrm{eV}(713$ $\mathrm{nm})$ at $19 \mathrm{~K}$ with the lowest-energy ZPL peaking at 1.833 $\mathrm{eV}$. Within the experimental uncertainty the three absorption bands peak at the same positions at $19 \mathrm{~K}$ and RT (Table I). An account of the thermal dependence of the optical spectra and band shifts is reported elsewhere. ${ }^{36}$

The triplet structure observed in the first ${ }^{4} A_{2} \rightarrow{ }^{4} T_{2}$ band is noteworthy. A discussion on its origin on the basis of the experimentally determined ${ }^{4} T_{2}$ and ${ }^{2} E$ ZPL energies is given in Sec. III F in order to clarify whether they are associated with Fano resonances or antiresonances. ${ }^{29-32}$ The energy of this first absorption band $(\Delta)$ and the Racah parameters indicate that $\Delta / B \approx 21$, this value corresponding to ${ }^{4} T_{2} \leftrightarrow{ }^{2} E$ crossing point for the ground-state $\left({ }^{4} A_{2}\right)$ equilibrium geometry, according to the TS diagram for $\mathrm{Cr}^{3+}$ [Fig. 1(a)]. The emission energy and the ZPL enable us to draw the configurational curves for $\mathrm{LiCaAlF}_{6}: \mathrm{Cr}^{3+}$ as depicted in Fig. 1(b). The ESCO would take place once the corresponding energy minima of ${ }^{4} T_{2}$ and ${ }^{2} E$ parabola would cross, i.e., when their ZPL energy equals: $E_{\mathrm{ZPL}}\left({ }^{4} T_{2}\right)=E_{\mathrm{ZPL}}\left({ }^{2} E\right)$. It must be noted that at ambient pressure ${ }^{4} T_{2}$ minimum $\left[E_{\mathrm{ZPL}}\left({ }^{4} T_{2}\right)\right.$ $=1.79 \mathrm{eV}]$ lies approximately $0.1 \mathrm{eV}$ below ${ }^{2} E$ minimum $\left[E_{\mathrm{ZPL}}\left({ }^{2} E\right)=1.88 \mathrm{eV}\right]$ indicating that the ESCO has not yet taken place and the PL is fully governed by the ${ }^{4} T_{2}$ first excited state yielding broadband ${ }^{4} T_{2} \rightarrow{ }^{4} A_{2}$ emission.

Following the TS diagram of Fig. 1(a), the absorption transitions correspond to vertical lines from ${ }^{4} A_{2}$ to excited states ${ }^{4} T_{i}(i=2,1 \mathrm{a}, 1 \mathrm{~b})$ at the ${ }^{4} A_{2}$ equilibrium geometry (i.e., $\Delta / B \approx 21)$. However, emission takes place from the first excited-state relaxed geometry that, according to the emission energy $\left(E_{\mathrm{emis}}=1.69 \mathrm{eV}\right)$, corresponds to $\Delta / B \approx 18$ what shows that ${ }^{4} T_{2}$ is the emitting state at ambient conditions (Figs. 1 and 2). An eventual ESCO transition would require reducing the energy difference between ${ }^{2} E$ and ${ }^{4} T_{2}$ at least by $\Delta E_{\min }=E_{\mathrm{ZPL}}\left({ }^{2} E\right)-E_{\mathrm{ZPL}}\left({ }^{4} T_{2}\right)=1.88-1.79=0.09 \mathrm{eV}(\mathrm{Sec}$. III F).

\section{B. Pressure effects on the excitation and emission spectra, and photoluminescence lifetime. Influence of the pressure- \\ induced trigonal-to-monoclinic structural phase transition}

Figure 1(b) depicts the configurational curves of the two emitting excited states as a function of pressure above, below and at the ESCO where both parabola minima (and their ZPL) coincide. Given that the PL transition rate from ${ }^{4} T_{2}$ is faster than from ${ }^{2} E\left({ }^{2} E \rightarrow{ }^{4} A_{2}\right.$ spin forbidden $),{ }^{2,9}$ an eventual narrow-line emission is expected at pressure conditions (or corresponding CF strength) well above the ESCO.

Figures 3 and 4 show the $\mathrm{LiCaAlF}_{6}: \mathrm{Cr}^{3+}$ emission spectra and several spectroscopic parameters in the 0-13 GPa pressure range, respectively. From $6 \mathrm{GPa}$ both broadband $\left({ }^{4} T_{2}\right)$ and narrow-line $\left({ }^{2} E\right)$ emissions coexist with identical radiative lifetimes due to thermalization processes. Some anomalies in the PL behavior of $\mathrm{Cr}^{3+}$ are observed at 7.0 $\pm 0.5 \mathrm{GPa}$ caused by the structural PT of $\mathrm{LiCaAlF}_{6}$, which was detected by $\mathrm{x}$-ray diffraction around $8 \mathrm{GPa} .^{13}$

Pressure-induced PT has important consequences on $\mathrm{Cr}^{3+}$ $\mathrm{PL}$ in $\mathrm{LiCaAlF}_{6}: \mathrm{Cr}^{3+}$. First, the PL band experiences an abrupt redshift $(-0.17 \mathrm{eV})$ upon pressure [Fig. 4(a)] from phase I to phase II producing an increase in the critical pressure needed for the ESCO to take place (Figs. 3 and 4). ${ }^{13}$ Second, the narrow features associated with ${ }^{2} E \rightarrow{ }^{4} A_{2}$ emission, peaking at $1.872 \mathrm{eV}$ at $6 \mathrm{GPa}$, completely disappear above the PT pressure and reappearing for P $>10 \mathrm{GPa}$ (Fig. 3). Third, the low-symmetry $\mathrm{Cr}^{3+}$ site in phase II reduces the PL lifetime from $172 \mu \mathrm{s}$ in phase I to $72 \mu \mathrm{s}$ in phase II [Fig. 4(c)] at ambient conditions due to the oscillatorstrength increase by the low-symmetry noncentrosymmetric $\mathrm{CF}$. These results prove that $\mathrm{Cr}^{3+} \mathrm{PL}$ is an efficient probe to detect pressure-induced PT in the host crystal. Both lifetime reduction and PL redshift can render attractive properties to the material as laser medium since PT enhances the absorption coefficient, whereas the emission broadening $(0.1 \mathrm{eV})$ extends the laser tunability.

An unexpected result is the lifetime reduction from 0 to 7 $\mathrm{GPa}$. In fact, due to the spin-forbidden character of 
(a)

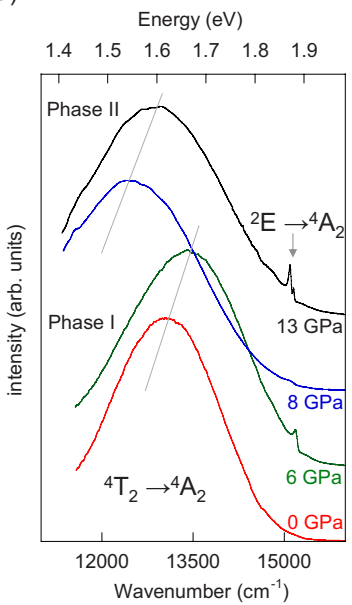

(b)

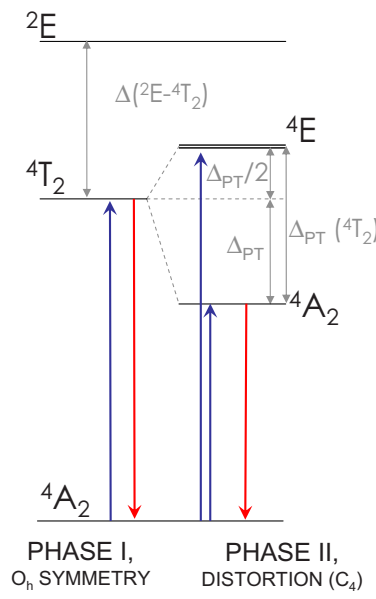

FIG. 3. (Color online) (a) Variation in $\mathrm{LiCaAlF}_{6}: \mathrm{Cr}^{3+}(2 \%) \mathrm{PL}$ spectrum in the $0-13 \mathrm{GPa}$ range at $300 \mathrm{~K}$. Each spectrum was obtained by time-resolved spectroscopy counting emitted photons during a three-lifetime interval after $50 \mathrm{~ns}$ pulsed excitation into the ${ }^{4} A_{2} \rightarrow{ }^{4} T_{1}(a)$ band using $\lambda_{\text {exc }}=412 \mathrm{~nm}$. (b) Energy-level diagram of the ${ }^{4} T_{2},{ }^{2} E$, and ${ }^{4} A_{2}$ states of $\mathrm{Cr}^{3+}$ in $\mathrm{LiCaAlF}_{6}$ Phase I (nearly $O_{h} \mathrm{CrF}_{6}^{3-}$ ) and Phase II (nearly $C_{4} \mathrm{CrF}_{6}^{3-}$ ). Note that the Phase ${ }^{4} T_{2}$ state splits into ${ }^{4} E$ and ${ }^{4} A_{2}$ by $\Delta_{\mathrm{PT}}\left({ }^{4} T_{2}\right)$ in Phase II. Their energy separation to ${ }^{4} T_{2}$ state center of gravity is $\frac{1}{3} \Delta_{\mathrm{PT}}\left({ }^{4} T_{2}\right)$ for ${ }^{4} E\left(C_{4}\right)$ and $\frac{2}{3} \Delta_{\mathrm{PT}}\left({ }^{4} T_{2}\right)=\Delta_{\mathrm{PT}}$ for ${ }^{4} A_{2}\left(C_{4}\right)$. It implies that the energy difference between ${ }^{4} T_{2}$ and ${ }^{2} E$ emitting states changes from $\Delta_{\mathrm{ZPL}}\left({ }^{2} E-{ }^{4} T_{2}\right)$ in Phase I to $\Delta_{\mathrm{ZPL}}\left({ }^{2} E-{ }^{4} T_{2}\right)+2 / 3 \Delta_{\mathrm{PT}}\left({ }^{4} T_{2}\right)$ in Phase II.

${ }^{2} E \rightarrow{ }^{4} A_{2}, \tau(P)$ should increase with pressure as ${ }^{4} T_{2}$ approaches ${ }^{2} E$ increasing its thermal population. Actually $\tau(P)$ increases an order of magnitude from $7 \mathrm{GPa}(\tau=100 \mu \mathrm{s})$ to $35 \mathrm{GPa}(\tau=2.7 \mathrm{~ms})$ beyond ESCO [Fig. 6(b)]. Hence pre-

(a)
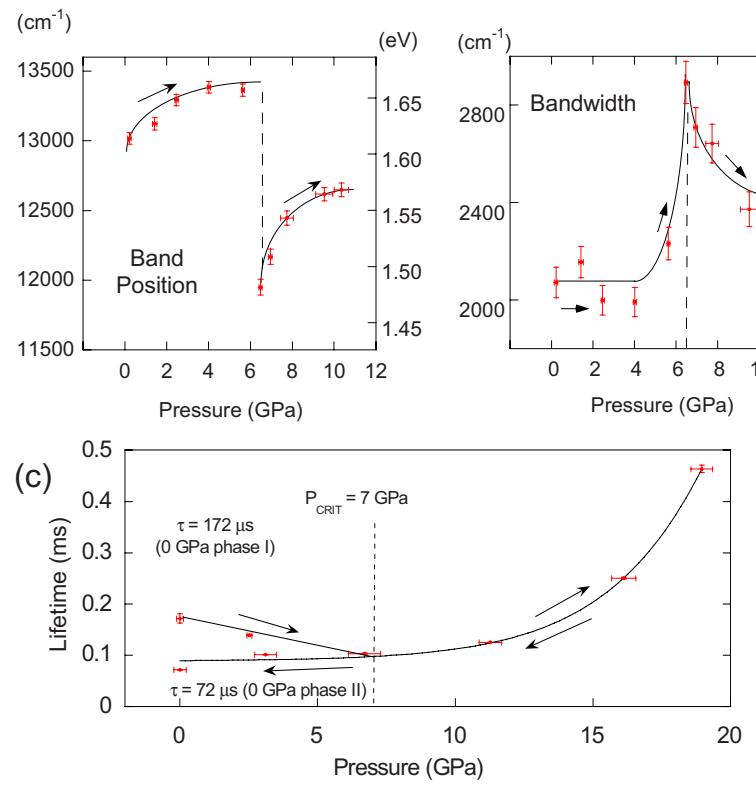

FIG. 4. (Color online) Variation in the (a) PL emission energy, (b) bandwidth, (c) and lifetime with pressure at $300 \mathrm{~K}$ around the Phase $\mathrm{I} \rightarrow$ Phase II phase transition at $P_{\mathrm{PT}}=7.0 \pm 0.5 \mathrm{GPa}$ in upstroke for (a) and (b) and in upstroke and downstroke for (c). transitional effects are responsible for the initial decrease in $\tau(P)$ observed in Fig. 4(c). Such effects also influence the energy and bandwidth, yielding PL broadening and lifetime reduction from $172 \mu$ s (phase I) to $72 \mu$ s (phase II) at ambient conditions (hysteresis). Interestingly, we observe that the high-pressure phase II remains stable upon pressure release at ambient conditions, thus revealing its first-order character with a hysteresis of at least $6 \mathrm{GPa}$ at RT.

\section{Pressure-induced photoluminescence from broadband to narrow-line emission}

Figures 5 and 6(a) show the evolution of RT $\mathrm{LiCaAlF}_{6}: \mathrm{Cr}^{3+}$ emission spectra in the 0-35 GPa pressure range. The variation illustrates how $\mathrm{Cr}^{3+}$ broadband emission $\left({ }^{4} T_{2} \rightarrow{ }^{4} A_{2}\right)$ progressively transforms into a two narrow-lines (R1 and R2) rubylike emission (spin-flip ${ }^{2} E \rightarrow{ }^{4} A_{2}$ transition) that becomes the dominant PL feature above $28 \mathrm{GPa}$. This result contrasts with previous measurements reporting $\mathrm{Cr}^{3+}$ narrow-line emission in $\mathrm{K}_{2} \mathrm{NaGaF}_{6}: \mathrm{Cr}^{3+}$ from about $6 \mathrm{GPa}$ at low temperature ${ }^{1,9,20,22}$ and experimentally demonstrates that a rubylike PL can be obtained in $\mathrm{Cr}^{3+}$-doped fluorides at RT but applying much higher pressure.

The initial broadband emission shifts to higher energy with pressure according to the increase in ${ }^{4} T_{2}$ energy with $\Delta$ with a pressure rate of $11 \mathrm{meV} / \mathrm{GPa}$ [Figs. 1(a) and 5(a)]. Besides broadband emission, the $\mathrm{Cr}^{3+} \mathrm{R} 1-\mathrm{R} 2$ lines appear at about $1.88 \mathrm{eV}(662 \mathrm{~nm})$ above $8 \mathrm{GPa}$ for $\mathrm{LiCaAlF}_{6}$ in phase II as is shown in Figs. 5(b) and 5(c). Their intensity increases with pressure at expenses of the ${ }^{4} T_{2}$ band and $\mathrm{LiCaAlF}_{6}: \mathrm{Cr}^{3+} \mathrm{PL}$ completely transforms to a rubylike emission above $28 \mathrm{GPa}$. Both R1 and R2 lines exhibit a linear dependence in the 5-35 $\mathrm{GPa}$ range

$$
\begin{gathered}
\lambda_{\mathrm{R} 1}(\mathrm{~nm})=660.9+0.146 \times P(\mathrm{GPa}) \\
\lambda_{\mathrm{R} 2}(\mathrm{~nm})=658.4+0.146 \times P(\mathrm{GPa}), \\
E_{\mathrm{R} 1}(\mathrm{eV})=1.876-0.41 \times 10^{-3} P(\mathrm{GPa}) \\
E_{\mathrm{R} 2}(\mathrm{eV})=1.883-0.40 \times 10^{-3} P(\mathrm{GPa}) .
\end{gathered}
$$

These lines are separated by $\Delta E=7 \mathrm{meV}(\Delta \lambda=2.5 \mathrm{~nm})$, which is about twice the difference between ruby $R$ lines: $\Delta E=3.6 \mathrm{meV}(\Delta \lambda=1.5 \mathrm{~nm}) .^{38}$ It implies that the lowenergy R1 line at $1.876 \mathrm{eV}$ is four times more intense than the R2 line at $1.883 \mathrm{eV}$ in agreement with their thermal populations at RT. Although the structural PT does not affect significantly the ZPL energy, it however has a strong influence on the ZPL intensity with respect to the broadband ${ }^{4} T_{2} \rightarrow{ }^{4} A_{2}$ intensity. In fact, the ${ }^{2} E \rightarrow{ }^{4} A_{2}$ splitting into R1 and $\mathrm{R} 2$ is as in ruby a direct consequence of the trigonal $\mathrm{CF}$ and the spin-orbit interaction. According to $\mathrm{X}$-ray diffraction data in $\mathrm{LiCaAlF}_{6},{ }^{13}$ the trigonal distortion of the $\left(\mathrm{AlF}_{6}\right)^{3-}$ octahedron in phase I is weaker than in phase II. The small $\mathrm{R} 1-\mathrm{R} 2$ splitting in the emission spectrum at $6 \mathrm{GPa}$ in comparison to the splitting at $13 \mathrm{GPa}$ confirms this feature.

The presence of $R$ lines in the emission spectrum of $\mathrm{LiCaAlF}_{6}: \mathrm{Cr}^{3+}$ enables an in situ pressure determination in the host crystal from the pressure shift rate of $0.146 \mathrm{~nm} / \mathrm{GPa}$. 

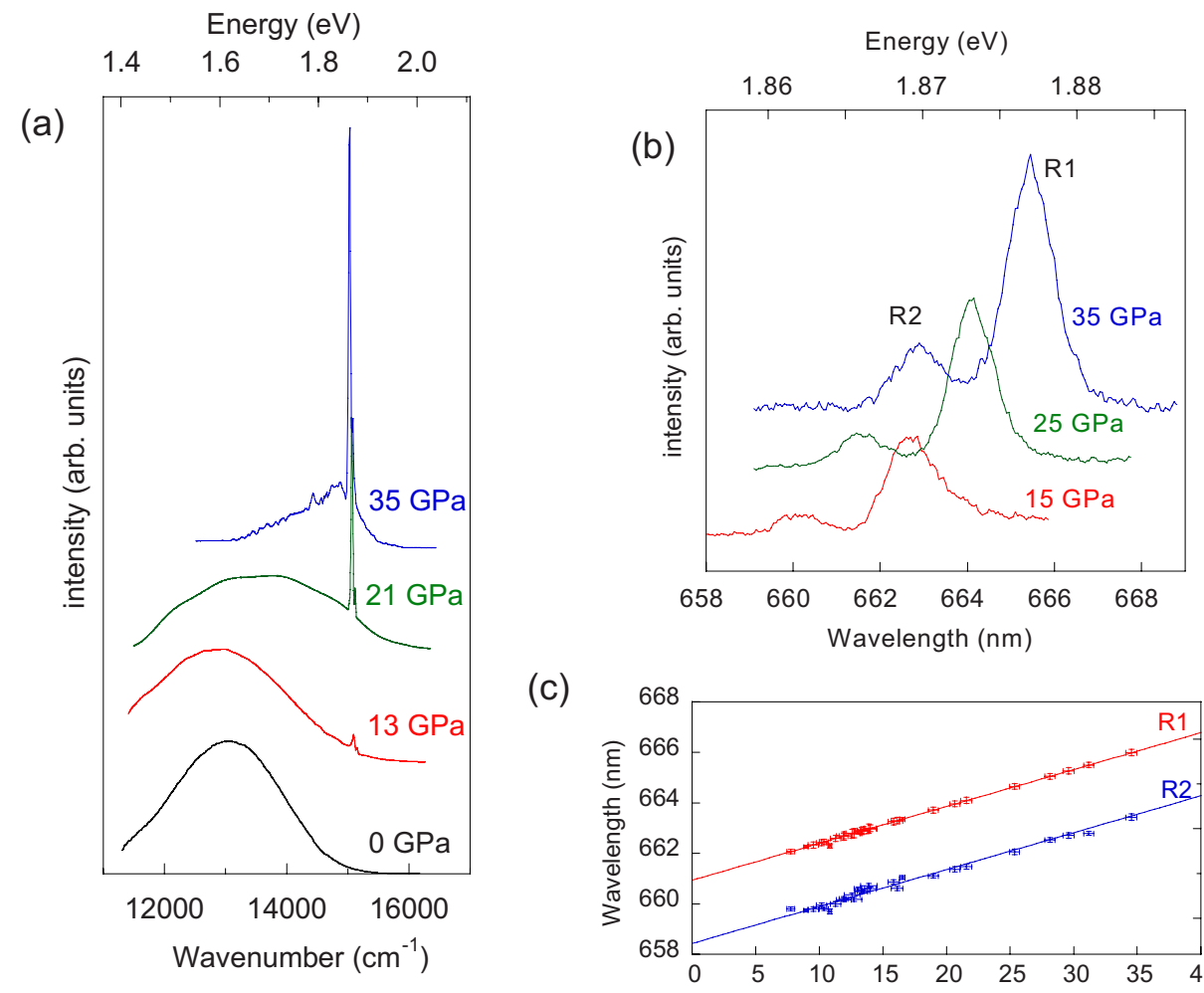

(c)

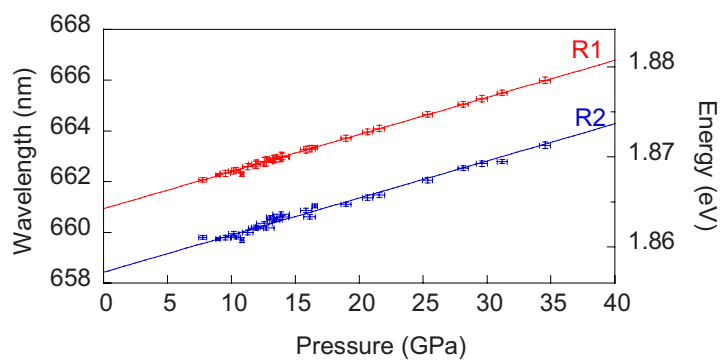

FIG. 5. (Color online) (a) Variation in the time-resolved emission spectrum of $\mathrm{LiCaAlF}_{6}: \mathrm{Cr}^{3+}$ with pressure in the $0-35 \mathrm{GPa}$ range at room temperature. Each spectrum was obtained by time-resolved spectroscopy counting emitted photons during three-lifetime interval after $50 \mathrm{~ns}$ pulsed excitation into the ${ }^{4} A_{2} \rightarrow{ }^{4} T_{1}(a)$ band using $\lambda_{\text {exc }}=412 \mathrm{~nm}$. (b) Pressure variation in $\mathrm{Cr}^{3+} \mathrm{R} 1$ and $\mathrm{R} 2$ lines in $\mathrm{LiCaAlF}_{6}: \mathrm{Cr}^{3+}$ (2\%). (c) Linear dependence of the R1 and R2 lines with pressure. The least-square linear fits are: $\lambda_{\mathrm{R} 1}(\mathrm{~nm})=660.9+0.146 \times P(\mathrm{GPa})$ and $\lambda_{\mathrm{R} 2}(\mathrm{~nm})=658.4+0.146 \times P(\mathrm{GPa})$ (units in $\mathrm{nm}$ and $\mathrm{GPa}$, respectively). The corresponding linear fits in energy units are: $E_{\mathrm{ZPL}}\left({ }^{2} E ; \mathrm{R} 1\right)$ $=1.876-0.00041 P$, and $E_{\mathrm{ZPL}}\left({ }^{2} E ; \mathrm{R} 2\right)=1.883-0.00040 P(\mathrm{eV}$ and $\mathrm{GPa})$.

(a)

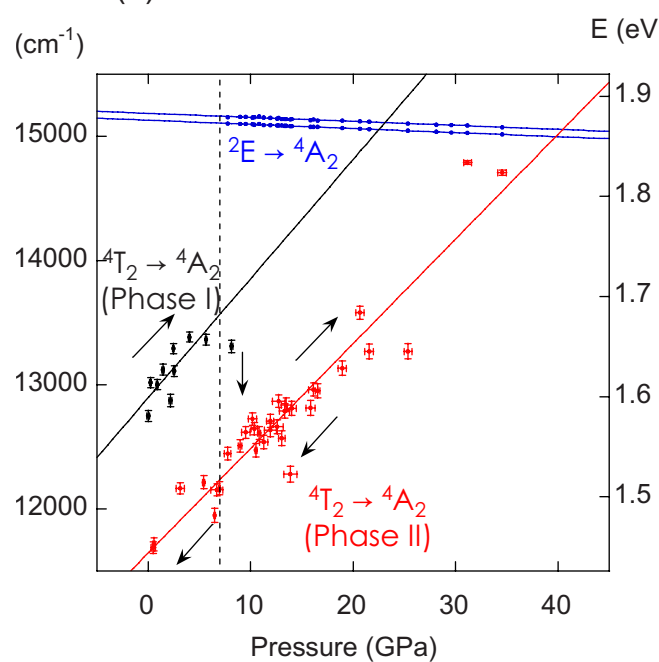

(b)

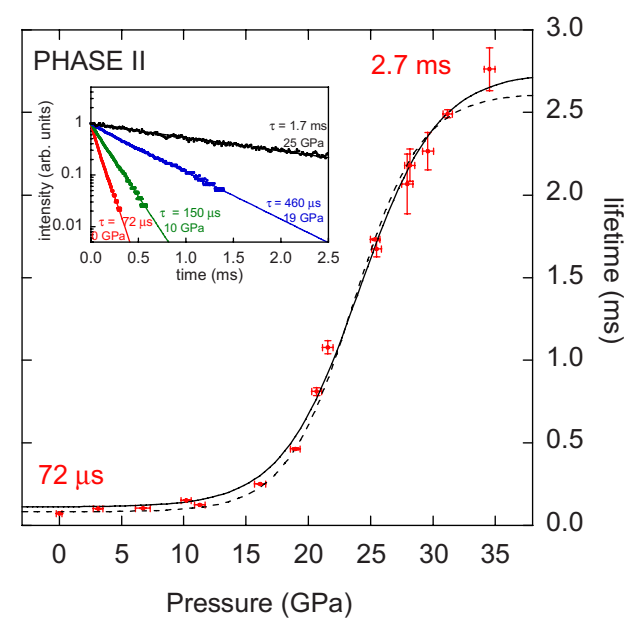

FIG. 6. (Color online) (a) Variation in $\mathrm{LiCaAlF}_{6}: \mathrm{Cr}^{3+}(2 \%) \mathrm{PL}$ spectrum in $0-35 \mathrm{GPa}$ pressure range at $300 \mathrm{~K}$, including the corresponding variations in the emission energy for the broadband ${ }^{4} T_{2} \rightarrow{ }^{4} A_{2}$ and $R$ lines ${ }^{2} E \rightarrow{ }^{4} A_{2}$. The solid lines represent least-square linear fits to the experimental points in phase I and II, and for $R$ lines (see Eqs. (2)). (b) Luminescence lifetime of $\mathrm{LiCaAlF}_{6}: \mathrm{Cr}^{3+}(2 \%)$ in phase II in the 0-35 GPa range at $300 \mathrm{~K}$. The $\tau(P)$ lines represent the calculated lifetime on the basis of two emitting excited states: ${ }^{4} T_{2}$ $(\tau=72 \mu \mathrm{s})$ and ${ }^{2} E(\tau=2.7 \mathrm{~ms})$ according to $\left(\mathrm{CrF}_{6}\right)^{3-}$ with $O_{\mathrm{h}}$ symmetry given by Eq. (1) (solid line), and $C_{4}$ symmetry by Eq. (3) (dashed line). The time-dependence emission decay at four different pressures is given as an inset. 
(a)

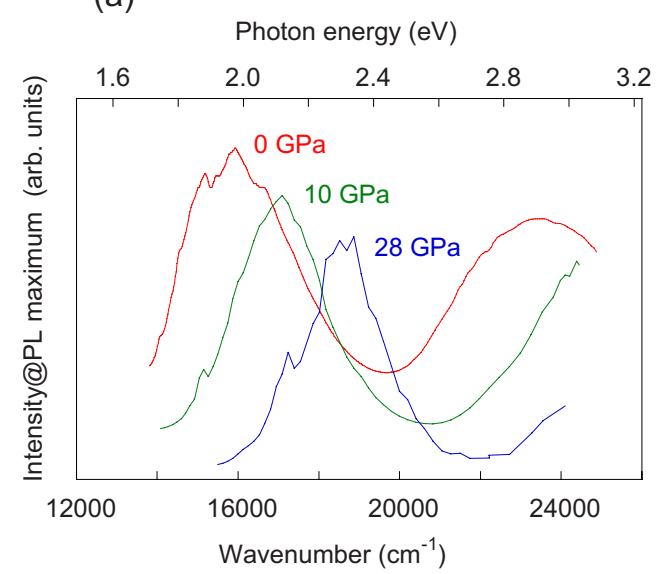

(b)

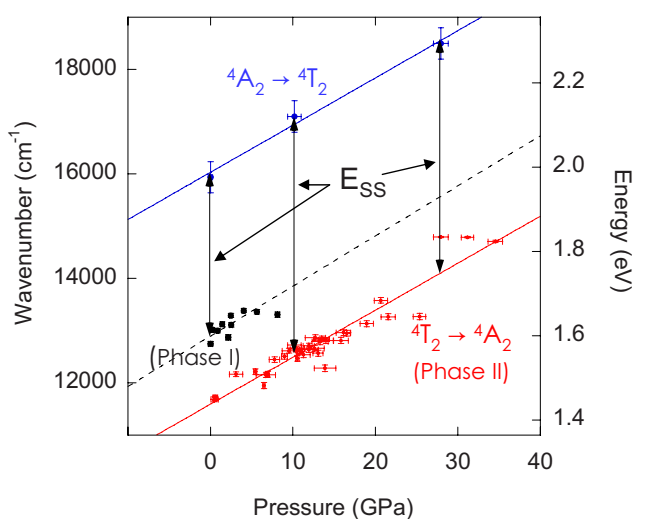

FIG. 7. (Color online) (a) Pressure dependence of the time-resolved excitation spectrum of $\mathrm{LiCaAlF}_{6}: \mathrm{Cr}^{3+}(2 \%)$. Each spectrum was obtained by measuring the PL intensity at the emission maximum as a function of the excitation wavelength using photon-counting techniques. Emitted photons were counted for a three-lifetime interval after 50 ns pulsed excitation for each excitation wavelength. The excitation spectrum was corrected for instrumental response and excitation intensity. (b) Pressure dependence of the excitation and corresponding emission energies associated with the ${ }^{4} A_{2} \leftrightarrow{ }^{4} T_{2}$ transition. The arrows indicate the magnitude of the Stokes shift.

By contrast the ruby $R$-shift rate is $0.365 \mathrm{~nm} / \mathrm{GPa}$ making it more sensitive to pressure changes. ${ }^{38,39}$ In spite of the smaller sensitivity of $\mathrm{LiCaAlF}_{6}: \mathrm{Cr}^{3+} R$ lines, their energy (or wavelength) dependence $E(P)$ follows a linear behavior in a wider pressure range than ruby thus extending at least up to $35 \mathrm{GPa}$. This allows us a precise determination of ${ }^{2} E$ energy at ambient conditions by extrapolating high-pressure data, what is crucial on discussing the Fano-type resonances in the first absorption band. ${ }^{40}$

\section{Lifetime measurements}

The PL evolution from broadband to narrow-line emission is accompanied by a progressive increase in the lifetime $\tau(P)$ from $72 \mu \mathrm{s}$ at ambient pressure to $2.7 \mathrm{~ms}$ at $35 \mathrm{GPa}$ for $\mathrm{LiCaAlF}_{6}: \mathrm{Cr}^{3+}$ in phase II [Fig. 6(b)] as the thermal population of ${ }^{4} T_{2}$ state decreases at expenses of ${ }^{2} E$. This effect is confirmed by the spectroscopically detected ${ }^{2} E$ and ${ }^{4} T_{2}$ ZPLs, the energy separation of which $\left(\Delta E_{\min }=\Delta_{\mathrm{ZPL}}\right)$ increases continuously with pressure [Fig. 6(a)]. The solid line in Fig. 6(b) corresponds to the lifetime fit to the equation

$$
\begin{gathered}
\tau^{-1}=\frac{12 w_{1}+4 w_{2} \exp \left(\frac{-\Delta_{\mathrm{ZPL}}}{k_{\mathrm{B}} T}\right)}{12+4 \exp \left(\frac{-\Delta_{\mathrm{ZPL}}}{k_{\mathrm{B}} T}\right)} \Rightarrow \\
\tau=\frac{12+4 \exp \left(\frac{-\Delta_{\mathrm{ZPL}}}{k_{\mathrm{B}} T}\right)}{12 w_{1}+4 w_{2} \exp \left(\frac{-\Delta_{\mathrm{ZPL}}}{k_{\mathrm{B}} T}\right)},
\end{gathered}
$$

where $w_{1}\left(=\tau_{1}^{-1}\right)$ and $w_{2}\left(=\tau_{2}^{-1}\right)$ are, respectively, ${ }^{4} T_{2} \rightarrow{ }^{4} A_{2}$ and ${ }^{2} E \rightarrow{ }^{4} A_{2}$ transition probabilities, being 12 and 4 their associated total degeneracy in a local $O_{h}$ symmetry $\left(\mathrm{CrF}_{6}\right)^{3-}$. $\Delta_{\text {ZPL }}$ represents the energy difference between both state minima.
Although the fitting quality is appealing, a more realistic description of $\tau(P)$ must however consider the actual structure of $\left(\mathrm{CrF}_{6}\right)^{3-}$ in the monoclinic $P 2_{1} / c$ phase II. Particularly, the loss of inversion center and the low-symmetry CF at the $\mathrm{Al}^{3+}$ site, ${ }^{13}$ make the $O_{h}$ model unrealistic. The $\mathrm{CF}$ distortion in phase II is mostly responsible for the lifetime decrease and the emission redshift at the PT [Fig. 4(c)], and for their respective pressure dependences. The doted line in Fig. 6(b) depicts $\tau(P)$ variations with model calculations according to the proposed scenario (cf. Sec. III E).

\section{E. Phase-transition effects in the photoluminescence properties of $\mathrm{LiCaAlF}_{6}: \mathrm{Cr}^{3+}$}

Figure 3(b) depicts the ${ }^{4} T_{2}$ state in $O_{h}$ (phase I) and $C_{4}$ (phase II), and Fig. 6 shows $E(P)$ and $\tau(P)$ variations according to models. The abrupt emission redshift, $\Delta_{\mathrm{PT}}=$ $-0.17 \mathrm{eV}$, at PT is associated with the ${ }^{4} T_{2}$ (phase I) splitting into ${ }^{4} E+{ }^{4} A_{2}$ (phase II). This effect can be hardly detected in excitation [Fig. $7(\mathrm{a})]$ since the energy of the first excitation band in $C_{4}$ actually corresponds to the centroid of the two ${ }^{4} E$ and ${ }^{4} A_{2}$ bands. According to Fig. 3(b) scenario, the ${ }^{4} T_{2}\left(O_{h}\right)$ splitting in phase II would be $\Delta_{\mathrm{PT}}\left({ }^{4} T_{2}\right)=3 \Delta_{\mathrm{PT}} / 2=-0.23 \mathrm{eV}$.

The PT-induced emission redshift has important consequences in the PL properties of $\mathrm{LiCaAlF}_{6}: \mathrm{Cr}^{3+}$. In the following sections we will discuss the PT effects on: (1) the ESCO associated pressure, (2) the lifetime, and (3) the Stokes shift.

\section{Phase-transition effects on $\mathrm{Cr}^{3+}$ spectra}

The ESCO pressure $\left(P_{\mathrm{ESCO}}\right)$ stabilizing ${ }^{2} E$ as the lowest excited state increases due to the ${ }^{4} T_{2} \rightarrow{ }^{4} A_{2}$ emission redshift in phase II. The ESCO energy, defined as $\Delta_{\mathrm{ESCO}}=E_{\mathrm{ZPL}}\left({ }^{2} E\right)$ $-E_{\mathrm{ZPL}}\left({ }^{4} T_{2}\right)$, increases from $0.086 \mathrm{eV}$ in phase I to $0.136 \mathrm{eV}$ in phase II (Fig. 8 and Table II). From Figs. 6-8, we obtained that the pressure variations in ZPL energy of ${ }^{4} T_{2}$ and ${ }^{2} E$ for phases I and II are given by 


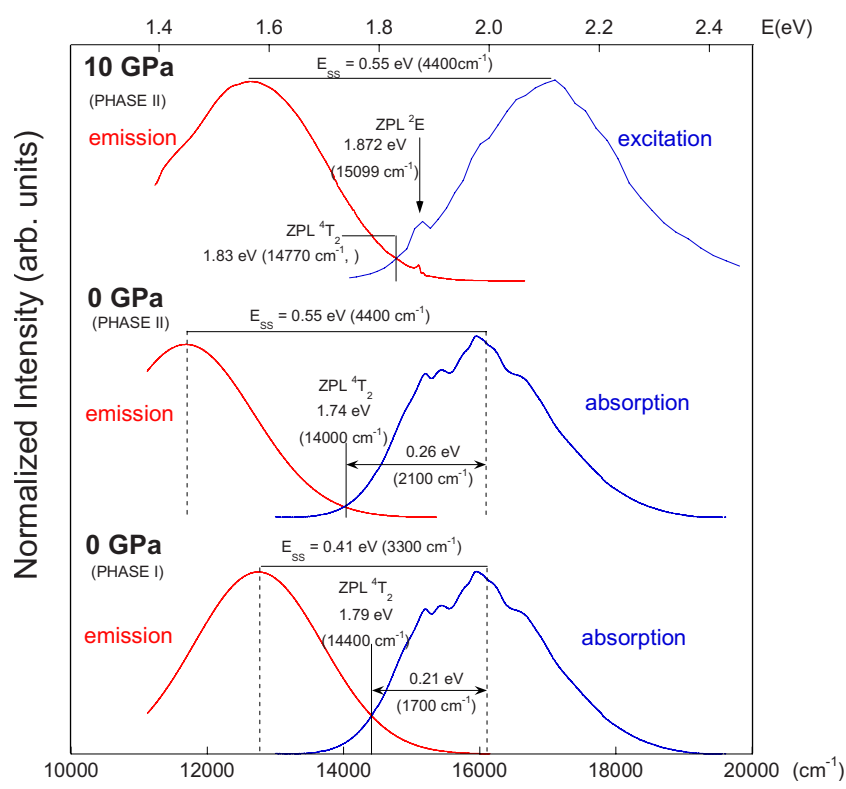

FIG. 8. (Color online) Time-resolved excitation and corresponding PL spectra of $\mathrm{LiCaAlF}_{6}: \mathrm{Cr}^{3+}(2 \%)$ at ambient pressure in Phases I and II (pressure release) and at $10 \mathrm{GPa}$. Stokes shift $\left(E_{\mathrm{SS}}\right)$ and zero-phonon line energies $\left(E_{\mathrm{ZPL}}\right)$ are also given.

$$
\begin{gathered}
E_{\mathrm{ZPL}}\left({ }^{2} E ; \mathrm{R} 1\right)=1.876-0.00041 P, \\
E_{\mathrm{ZPL}}\left({ }^{2} E ; \mathrm{R} 2\right)=1.883-0.00040 P, \\
E_{\mathrm{ZPL}}\left({ }^{4} T_{2-\mathrm{I}}\right)=1.79+0.011 P(\text { Phase } \mathrm{I}),
\end{gathered}
$$

TABLE II. Room-temperature excitation and zero-phonon line energies corresponding to the first absorption band of

\begin{tabular}{|c|c|c|c|}
\hline $\begin{array}{l}P \\
(\mathrm{GPa})\end{array}$ & $\begin{array}{c}E_{\mathrm{exc}}\left({ }^{4} A_{2} \rightarrow{ }^{4} T_{2}\right) \\
\quad(\mathrm{eV})\left(\mathrm{cm}^{-1}\right)\end{array}$ & $\begin{array}{c}E_{\mathrm{ZPL}}\left({ }^{4} A_{2} \leftrightarrow{ }^{4} T_{2}\right) \\
\quad(\mathrm{eV})\left(\mathrm{cm}^{-1}\right)\end{array}$ & $\begin{array}{c}E_{\mathrm{ZPL}}-E_{\mathrm{exc}} \\
(\mathrm{eV})\left(\mathrm{cm}^{-1}\right)\end{array}$ \\
\hline 0 (Phase I) & $\begin{array}{c}2.00 \pm 0.04 \\
(16100 \pm 300)\end{array}$ & $\begin{array}{c}1.79 \pm 0.01 \\
(14400 \pm 100)\end{array}$ & $\begin{array}{c}0.21 \pm 0.05 \\
(1700 \pm 400)\end{array}$ \\
\hline 0 (Phase II) & $\begin{array}{c}2.00 \pm 0.04 \\
(16100 \pm 300)\end{array}$ & $\begin{array}{c}1.74 \pm 0.01 \\
(14000 \pm 100)\end{array}$ & $\begin{array}{c}0.26 \pm 0.05 \\
(2100 \pm 400)\end{array}$ \\
\hline 10 (Phase II) & $\begin{array}{c}2.12 \pm 0.04 \\
(17100 \pm 300)\end{array}$ & $\begin{array}{c}1.83 \pm 0.01 \\
(14800 \pm 100)\end{array}$ & $\begin{array}{c}0.29 \pm 0.05 \\
(2300 \pm 400)\end{array}$ \\
\hline 28 (Phase II) & $\begin{array}{c}2.29 \pm 0.04 \\
(18500 \pm 300)\end{array}$ & $\begin{array}{c}2.03 \pm 0.01 \\
(16400 \pm 100)\end{array}$ & $\begin{array}{c}0.26 \pm 0.05 \\
(2100 \pm 400)\end{array}$ \\
\hline \multicolumn{4}{|c|}{ Stokes shift $E_{\mathrm{SS}}\left({ }^{4} A_{2} \rightarrow{ }^{4} T_{2}\right)$} \\
\hline $\begin{array}{l}P \\
(\mathrm{GPa})\end{array}$ & 0 (Phase I) & 0 (Phase II) & 10 (Phase II) \\
\hline $\begin{array}{l}(\mathrm{eV}) \\
\left(\mathrm{cm}^{-1}\right)\end{array}$ & $\begin{array}{c}0.41 \pm 0.04 \\
(3300 \pm 300)\end{array}$ & $\begin{array}{c}0.55 \pm 0.04 \\
(4400 \pm 300)\end{array}$ & $\begin{array}{c}0.55 \pm 0.04 \\
(4400 \pm 300)\end{array}$ \\
\hline
\end{tabular}
$\mathrm{LiCaAlF}_{6}: \mathrm{Cr}^{3+}$ as a function of pressure. The associated Stokes shift, defined as $E_{\mathrm{SS}}=E_{\text {exc }}-E_{\text {emis }}$, are given below.

$$
\begin{aligned}
E_{\mathrm{ZPL}}\left({ }^{4} T_{2-\mathrm{II}}\right)= & 1.74+0.011 P(\text { Phase } \mathrm{II}) \\
& \times(E \text { in } \mathrm{eV} \text { and } P \text { in } \mathrm{GPa}) .
\end{aligned}
$$

Assuming that the pressure dependence of ${ }^{4} T_{2}$ ZPL energy is the same as for the emission band maximum, we estimate from Eq. (2) and Table II that ESCO in $\mathrm{LiCaAlF}_{6}: \mathrm{Cr}^{3+}$ takes place at a critical pressure of $7.5 \mathrm{GPa}$ in phase I and 12.4 $\mathrm{GPa}$ in phase II. This increase in $P_{\mathrm{ESCO}}$ is responsible for the disappearance of the ${ }^{2} E$ lines in the emission spectrum at 8 GPa after the PT pressure [Fig. 3(a)]. This result is confirmed by the excitation and emission spectra at $10 \mathrm{GPa}$ shown in Figs. 6(a) and 8. The ZPL for ${ }^{4} T_{2-\mathrm{II}}$ and ${ }^{2} E$ at $10 \mathrm{GPa}$ and RT can be obtained from Fig. 8 and have values of 1.83 and $1.872 \mathrm{eV}$, respectively. This means that ${ }^{4} T_{2-\mathrm{II}}$ is still the lowlying excited state at $10 \mathrm{GPa}$ and not ${ }^{2} E$. From the ${ }^{4} T_{2} \mathrm{ZPL}$ energy at $10 \mathrm{GPa}$ (Fig. 8), we can now improve our previous estimates on the ESCO pressure thus obtaining $P_{\mathrm{ESCO}}$ $=13.8 \mathrm{GPa}$ for $\mathrm{LiCaAlF}_{6}: \mathrm{Cr}^{3+}$ in phase II. It is worth noting that the relative emission intensity associated with ${ }^{2} E$ and ${ }^{4} T_{2}$ is proportional to their Boltzmann population and respective transition probability. The observation of weak $R$-line emission below the ESCO pressure, in spite of being ${ }^{4} T_{2}$ mostly populated, is due to the narrow peak width of ${ }^{2} E$. This allows us to observe ${ }^{2} E$ in the emission spectrum at 10 $\mathrm{GPa}$ though its relative intensity is only $0.2 \%$.

\section{Phase-transition effects on the photoluminescence lifetime}

The emission lifetime $\tau(P)$ changes in phase II as consequence of the ${ }^{4} T_{2}$ splitting and the corresponding transition rate due to pressure-induced PT. According to energy levels of Fig. 3(b), $\tau(P)$ in phase II is given by

$$
\tau(P)=\frac{\left[4+8 \exp \left(\frac{-\Delta_{\mathrm{PT}}}{k_{\mathrm{B}} T}\right)\right]+4 \exp \left(\frac{-\Delta_{\mathrm{ZPL}}}{k_{\mathrm{B}} T}\right)}{w_{1}\left[4+8 \exp \left(\frac{-\Delta_{\mathrm{PT}}}{k_{\mathrm{B}} T}\right)\right]+4 w_{2} \exp \left(\frac{-\Delta_{\mathrm{ZPL}}}{k_{\mathrm{B}} T}\right)},
$$

where $\Delta_{\mathrm{PT}}=\frac{2}{3} \Delta_{\mathrm{PT}}\left({ }^{4} T_{2}\right)$ is the energy difference between ${ }^{4} T_{2-\mathrm{I}}$ and ${ }^{4} A_{2}\left({ }^{4} T_{2-\text { II }}\right)$ states, $\Delta_{\mathrm{PT}}\left({ }^{4} T_{2}\right)$ being the ${ }^{4} T_{2}$ splitting in Phase II [Fig. 3(b)], and factors 4 and 8 refer to ${ }^{4} A_{2}$ and ${ }^{4} E$ state degeneracy, respectively. $\Delta_{\mathrm{ZPL}}=0.136-\alpha P$ is the energy difference between ${ }^{2} E$ and ${ }^{4} A_{2}\left({ }^{4} T_{2-\text { II }}\right)$ ZPLs and the fit parameter $\alpha$ represents the difference between pressure derivatives of $E_{\mathrm{ZPL}}(P)$ for both states. Assuming that the emission band maximum of ${ }^{4} A_{2}\left({ }^{4} T_{2-I I}\right)$ and its ZPL have the same pressure dependence then $\alpha$ is similar to $\alpha=0.011 \mathrm{eV} / \mathrm{GPa}$. Note that Eq. (3) reduces to Eq. (1) in Phase I where $\Delta_{\mathrm{PT}}\left({ }^{4} T_{2}\right)=0$. The dashed line of Fig. 6(b) shows the lifetime data fit to Eq. (3) with: $\Delta_{\mathrm{PT}}\left({ }^{4} T_{2}\right)=0.23 \mathrm{eV} ; w_{1}=12$ $\times 10^{3} \mathrm{~s}^{-1}$ and $w_{2}=0.38 \times 10^{3} \mathrm{~s}^{-1} ; \alpha=0.0095(10) \mathrm{eV} / \mathrm{GPa}$, $\alpha$ being similar to that derived spectroscopically.

Interestingly, the pressure required to get mostly $R$-line $\mathrm{PL}$ is $28 \mathrm{GPa}$ (Figs. 5 and 6). At this pressure the ${ }^{4} T_{2 \text {-II }}$ state is $0.17 \mathrm{eV}$ above ${ }^{2} E$ and the ESCO around $13 \mathrm{GPa}$ has been clearly surpassed. Such a strong pressure requirement for a major ${ }^{2} E$ PL is due to the long-lived ${ }^{2} E$ state $\left(w_{2}^{-1}=\tau_{2}\right.$ $=2.6 \mathrm{~ms})$ compared to the short lived ${ }^{4} T_{2} \quad\left(w_{1}^{-1}=\tau_{1}\right.$ 
$=80 \mu \mathrm{s})$. Although ${ }^{4} T_{2 \text {-II }}$ is less populated than ${ }^{2} E$ at 15 $\mathrm{GPa}$, it emits faster yielding a rapid depopulation of ${ }^{2} E$ into ${ }^{4} T_{2}$ in order to preserve the Boltzmann population between the two emitting states. The pressure required to get simply $R$-line emission in the PL spectrum must be higher than 25 $\mathrm{GPa}$ according to data of Fig. 6(a); or equivalently the energy separation between their ZPL should be higher than $\Delta_{\mathrm{ZPL}} \approx 0.15 \mathrm{eV}$.

\section{Phase-transition effects on the Stokes shift}

The PL Stokes shift, $E_{\mathrm{SS}}$, defined as the difference between emission and excitation energies: $E_{\mathrm{SS}}=E_{\mathrm{exc}}-E_{\mathrm{emis}}$, does not practically change with pressure. Although recent results on $\mathrm{Cr}^{3+}$ in fluoroelpasolites have shown that $E_{\mathrm{SS}}$ undergoes a slight increase with pressure, ${ }^{9}$ this work establishes that $E_{\mathrm{SS}}$ in $\mathrm{LiCaAlF}_{6}: \mathrm{Cr}^{3+}$ remains constant with $P$ as is shown in Fig. 7(b) and Table II. $E_{\mathrm{SS}}$ increases from 0.41 to $0.55 \mathrm{eV}$ when $\mathrm{LiCaAlF}_{6}$ passes from phase I to phase II, pointing out that a $\mathrm{LiCaAlF}_{6}: \mathrm{Cr}^{3+}$ four-level laser would be improved if $\mathrm{LiCaAlF}_{6}$ phase II was used instead of phase I.

\section{F. Origin of the Fano resonance in the ${ }^{4} A_{2} \rightarrow{ }^{4} T_{2}+{ }^{2} E+{ }^{2} T_{1}$ absorption band}

There is some controversy in elucidating the origin of the triplet structure in the ${ }^{4} A_{2} \rightarrow{ }^{4} T_{2}+{ }^{2} E+{ }^{2} T_{1}$ first absorption band as due to Fano resonance or antiresonance. ${ }^{9}$ It is well known that this triplet structure is due to orbital mixing between the broad ${ }^{4} T_{2}$ and narrow ${ }^{2} E+{ }^{2} T_{1}$ excited states by spin-orbit interaction. This effect is maximum in those systems showing $\operatorname{ESCO}(\Delta / B \approx 21)$ like in $\mathrm{LiCaAlF}_{6}: \mathrm{Cr}^{3+}$. Whether the interaction between ${ }^{2} E$ (or ${ }^{2} T_{1}$ ) and ${ }^{4} T_{2}$ through spin-orbit interaction gives rise to a Lorentzian, dispersionlike or inverted Lorentzian in the absorption spectrum, we are dealing with Fano resonance, dispersionlike or Fano antiresonance (inset of Fig. 9), respectively. ${ }^{31}$ The pressure results shown through Figs. 3-8 are worthy in unraveling the origin of the Fano interaction (Fig. 9). Previous reports, mainly based on band-shape analysis, ascribed such resonant features to Fano antiresonances, ${ }^{29-32}$ as the spectral structure around ${ }^{2} E+{ }^{2} T_{1}$ corresponds to a dip in the emission band (Fano antiresonance) rather than to a hump (Fano resonance) or dispersionlike features. According to recent findings, $, 9,29-32,40,41$ the resonance origin can be clarified when ${ }^{2} E$ energy is exactly known and pressure spectroscopy enables us to obtain the ${ }^{2} E$ energy at ambient conditions: $E_{\mathrm{ZPL}}\left({ }^{2} E\right)=1.876 \mathrm{eV}(\mathrm{R} 1)$ and $1.883 \mathrm{eV}(\mathrm{R} 2)$ at $P=0$ [Eq. (2)]. This R2 $\left({ }^{2} E\right)$ energy (marked for comparison purposes in the first absorption band of Fig. 9) coincides with the first resonance maximum, clearly revealing that first ${ }^{2} E \leftrightarrow{ }^{4} T_{2}$ structure in $\mathrm{LiCaAlF}_{6}: \mathrm{Cr}^{3+}$ corresponds to a Fano resonance. Therefore ${ }^{2} E$ energy can be directly obtained as the first maximum of the absorption fine structure. However a similar analysis cannot be made for ${ }^{2} T_{1}$ since the corresponding line is missed in the absorption and emission spectra. However band-shape analysis suggests that ${ }^{2} T_{1}$ and ${ }^{4} T_{2}$ interact as a Fano antiresonance as is shown by a dip in Fig. 9 fit, finding $E_{\mathrm{ZPL}}\left({ }^{2} T_{1}\right)=2.030 \mathrm{eV}$. The present analysis can be considered fairly good if we take into account that only a single

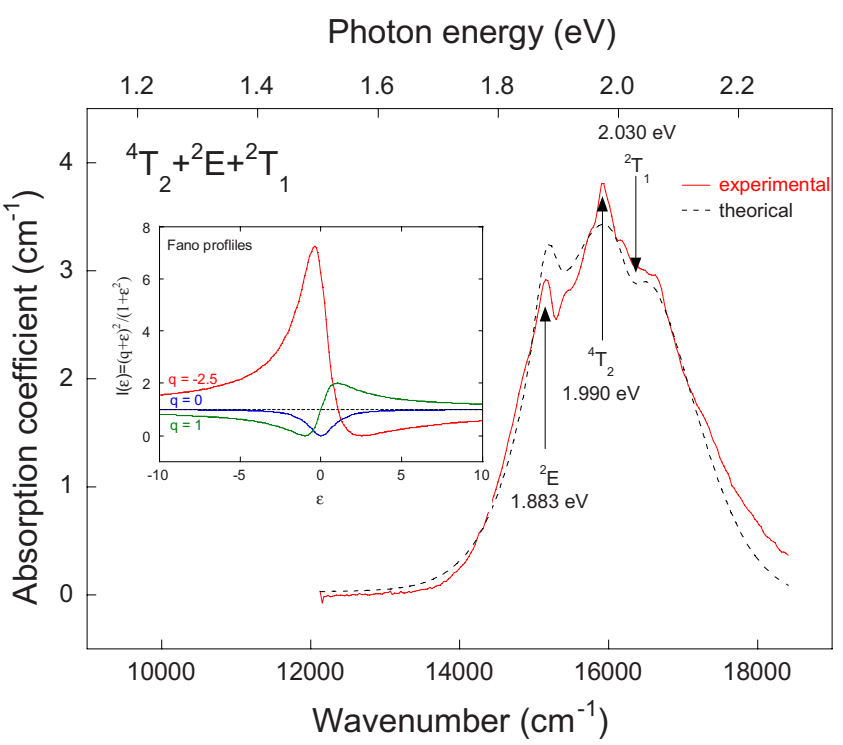

FIG. 9. (Color online) First absorption band ${ }^{4} A_{2} \rightarrow{ }^{4} T_{2}+{ }^{2} E$ $+{ }^{2} T_{1}$ in $\mathrm{LiCaAlF}_{6}: \mathrm{Cr}^{3+}(2 \%)$ at ambient conditions. The humplike and diplike features at 1.883 and $2.030 \mathrm{eV}$ are associated with Fano resonances between the ${ }^{4} T_{2}(F)$ broadband and ${ }^{2} E(G)$ and ${ }^{2} T_{1}(G)$ narrow peaks, respectively. The solid line corresponds to the best Gaussian fit to the overall broadband representing the absorption background of ${ }^{4} T_{2}$ broadband and two Fano resonances with profiles $I(\varepsilon)=\frac{(q+\varepsilon)^{2}}{1+\varepsilon^{2}}$ where $\varepsilon=\left(E-E_{0}\right) / \Gamma, E_{0}$ and $\Gamma$ being the energy and width of the resonances (Refs. 40 and 41 ). The ${ }^{2} E$ energy $E_{\mathrm{ZPL}}=1.883 \mathrm{eV}$, obtained from pressure experiments, confirms ${ }^{4} T_{2} \leftrightarrow{ }^{2} E$ resonance as a protuberance in the optical spectra. The profile analysis suggests that ${ }^{2} T_{1}$ state produces a Fano antiresonance with a dip at $2.030 \mathrm{eV}$. Note that the character of the two resonances is reflected by the enhancement (resonance) or diminution (antiresonance) absorption intensity with respect to ${ }^{4} T_{2}$ absorption background according to different possible Fano profiles given in the inset: Fano resonance $(q=-2.5)$; Fano antiresonance $(q=0)$; or dispersionlike resonance $(q=1)$.

Gaussian was used as an effective "density of states" for ${ }^{4} T_{2}$ and two Fano profiles for ${ }^{2} E$ and ${ }^{2} T_{1}$, the position of the former was determined from pressure data. The lack of a perfect match between simulated and experimental spectra in Fig. 9 is due to the presence of some vibronic features in the experimental absorption band that are not taken explicitly into account in our simplified model. It must be noted that the energy difference between ${ }^{2} E$ and ${ }^{2} T_{1}, \Delta E$ $=1.883-2.030=-0.147 \mathrm{eV}$, is higher than the estimated from the TS diagram: $\Delta E \approx B=-0.09 \mathrm{eV}$, what reflects the additional contribution due to the spin-orbit interaction. ${ }^{9,14}$

The Fano resonance weight in the first absorption band drastically diminishes as ${ }^{2} E$ and ${ }^{4} T_{2}$ become far apart at higher pressure, their excitation energies being 1.872 and $2.12 \mathrm{eV}$ at $10 \mathrm{GPa}$, respectively (Fig. 8 and Table II). Moreover, ${ }^{2} E$ excitation peak is much weaker than ${ }^{4} T_{2}$ band thus confirming that there is an important decoupling between the two states in the excitation spectrum at $10 \mathrm{GPa}$.

At $28 \mathrm{GPa} \mathrm{Cr}^{3+}$ in $\mathrm{LiCaAlF}_{6}: \mathrm{Cr}^{3+}$ emits only $R$ lines at 1.864 and $1.872 \mathrm{eV}\left({ }^{2} E\right)$. This situation is rather similar to ruby at ambient conditions where the ${ }^{4} A_{2} \rightarrow{ }^{2} E$ spin-flip transition is detected as a tiny feature at $1.786 \mathrm{eV}$ mounted on 


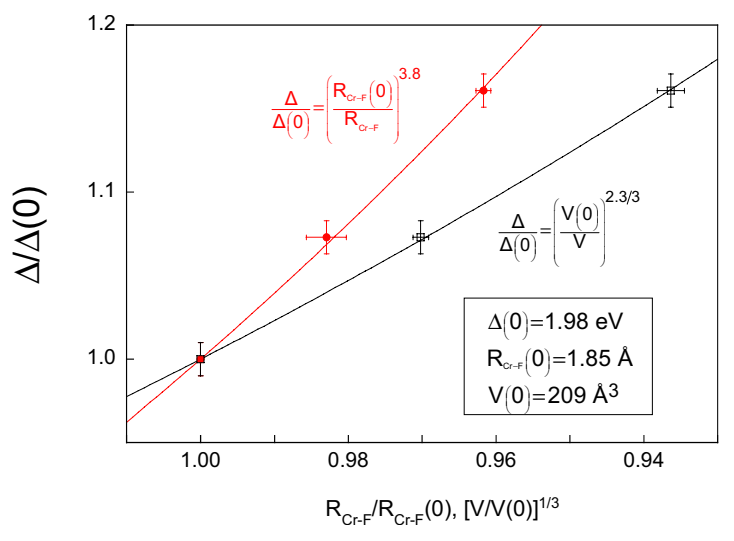

FIG. 10. (Color online) Dependence of the crystal-field strength $\Delta$ at $\mathrm{Cr}^{3+}$ with the crystal volume $(V)$ derived from the $\mathrm{LiCaAlF}_{6}$ equation of state (in squares) (Ref. 13). $\Delta$ dependence with the Cr-F distance $\left(R_{\mathrm{Cr}-\mathrm{F}}\right)$ derived from $\mathrm{CrF}_{6}^{3-}$ local equation of state taking $R_{\mathrm{Cr}-\mathrm{F}}(0)=R_{0}=1.85 \AA$ (in circles). $\Delta$ was obtained from the excitation spectra of Fig. 7.

the low-energy tail of the intense ${ }^{4} A_{2} \rightarrow{ }^{4} T_{2}$ absorption band peaking at about $2.25 \mathrm{eV}^{38}$ As a result, ruby PL consists of two $R$ lines ${ }^{2} E \rightarrow{ }^{4} A_{2}$ separated $3.6 \mathrm{meV}$ in contrasts to $\mathrm{LiCaAlF}_{6}: \mathrm{Cr}^{3+}$ at $10 \mathrm{GPa}$, the PL of which consists of both broadband ${ }^{4} T_{2} \rightarrow{ }^{4} A_{2}$ and $R$ lines ${ }^{2} E \rightarrow{ }^{4} A_{2}$ simultaneously. Although emission from ${ }^{4} T_{2}$ is missed at $28 \mathrm{GPa}$, the ${ }^{4} A_{2}$ $\rightarrow{ }^{4} T_{2}$ excitation band is located at $2.29 \mathrm{eV}$, providing an energy difference between ${ }^{2} E$ and ${ }^{4} T_{2}$ of $0.43 \mathrm{eV}$, which is similar to $0.46 \mathrm{eV}$ encountered for ruby at ambient conditions. The $\mathrm{CF}$ strength in ruby at ambient pressure is attained in $\mathrm{LiCaAlF}_{6}: \mathrm{Cr}^{3+}$ at $30 \mathrm{GPa}$ [Fig. 7; Eq. (2)]. These results confirm the role of the $\mathrm{CF}$ strength governing PL properties of $\mathrm{Cr}^{3+}$ irrespective of whether the required $\mathrm{CF}$ conditions are produced either by strongly $\sigma$-bonding ligands (nephelauxetic series $\mathrm{F} \rightarrow \mathrm{O} \rightarrow \mathrm{N}$ ) or under high-pressure conditions.

\section{G. Crystal-field dependence on the crystal volume and Cr-F distance}

According to the TS diagram [Fig. 1(a)], the CF splitting $(\Delta)$ is directly obtained from the band maximum of the timeresolved excitation spectra (Fig. 7). Through x-ray diffraction data of $\mathrm{LiCaAlF}_{6}$ in the $0-12 \mathrm{GPa}$ range ${ }^{13}$ and the corresponding equation of state (EOS) we derived the $\mathrm{CF}$ strength dependence on the crystal volume $\Delta(V)$ whose data are represented in Fig. 10. The variation has been fit to a semiempirical CF model through the equation: $\frac{\Delta}{\Delta(0)}$ $=\left[\frac{V}{V(0)}\right]^{-n / 3}$. We find an exponent $n=2.3(0.1)$. Note that this exponent is smaller than the one derived from $a b$ initio calculations of $\Delta\left(R_{\mathrm{Cr}-\mathrm{F}}\right)(n=4.3)$ for $\mathrm{CrF}_{6}^{3-}$ as a function of the $\mathrm{Cr}-\mathrm{F}$ bond distance. ${ }^{42-44}$ This behavior is quite general on comparing the variation of $\Delta$ with the crystal volume $V$ as indicated elsewhere. ${ }^{45,46}$ The measured exponents, named $n K$ in Refs. 45 and 46, are usually smaller than $5(K<1)$. However, localized systems such as transition-metal ions and rare earths in fluorides and oxides must be better compared with the local variation in the complex volume rather than with the crystal volume.
The deviation of $n$ (or $n K$ ) from the calculated value is probably due to lattice relaxation around $\mathrm{Cr}^{3+}$ making the compressibility of the $\left(\mathrm{CrF}_{6}\right)^{3-}$ octahedron different from the $\mathrm{LiCaAlF}_{6}$ bulk compressibility and thus causes a different $\Delta$ variation with $V^{1 / 3}$ and $R_{\mathrm{Cr}-\mathrm{F}}$. Recent PL studies on $\mathrm{Cr}^{3+}$ along fluoroelpasolite series have also shown an anomalous variation in $\Delta\left(R_{\mathrm{Cr}-\mathrm{F}}\right) \propto R_{\mathrm{Cr}-\mathrm{F}}^{-n}$ with $n=3.3$ (Ref. 9). This unusual dependence was attributed to Fano resonance effects. Nevertheless such effects are minimized in $\mathrm{LiCaAlF}_{6}: \mathrm{Cr}^{3+}$ at high pressure since Fano resonance strongly diminishes for $P>10 \mathrm{GPa}$ (Figs. 7 and 8). In fact, $n=3.8(0.3)$ is obtained when plotting $\Delta$ vs $R_{\mathrm{Cr}-\mathrm{F}}$ instead of $\Delta\left(V^{1 / 3}\right)$ (Fig. 10). $R_{\mathrm{Cr}-\mathrm{F}}$ was obtained from the $\left(\mathrm{CrF}_{6}\right)^{3-}$ local EOS by fitting $R_{\mathrm{Cr}-\mathrm{F}}(P)$ data for $\mathrm{K}_{2} \mathrm{NaGaF}_{6}: \mathrm{Cr}^{3+},{ }^{21}$ to a Murnaghan EOS

$$
R_{\mathrm{Cr}-\mathrm{F}}(P)=R_{\mathrm{Cr}-\mathrm{F}}(0)\left(1+\frac{B^{\prime} P}{B_{0}}\right)^{-1 / 3 B^{\prime}}
$$

obtaining $B_{0}=172 \mathrm{GPa} ; B^{\prime}=5.3$; and $R_{\mathrm{Cr}-\mathrm{F}}(0)=1.85 \AA$ (Ref. 9). The host crystal structure with $R_{\mathrm{Al}-\mathrm{F}}(0)=1.806 \AA$ (Ref. 35 ) eventually modulates the actual $\mathrm{Cr}-\mathrm{F}$ bond length around its equilibrium value in $\mathrm{LiCaAlF}_{6}: \mathrm{Cr}^{3+}$ at ambient conditions: $R_{\mathrm{Cr}-\mathrm{F}}(0)=1.85 \AA$. This procedure provides a fairly agreement between experimental $(n=3.8)$ and calculated $(n=4.3)$ exponent, ${ }^{43,44}$ thus reinforcing that $\Delta$ mainly scales with the local $\mathrm{Cr}-\mathrm{F}$ distance rather than with $V^{1 / 3}$.

\section{CONCLUSIONS}

A relevant conclusion of this study is the high pressure required $(28 \mathrm{GPa})$ to transform $\mathrm{LiCaAlF}_{6}: \mathrm{Cr}^{3+}$ broadband PL to a rubylike $R$-line emission even though ESCO was already attained at $6 \mathrm{GPa}$. This behavior is due to the different transition rates of ${ }^{4} T_{2}$ and ${ }^{2} E$ states with $\tau\left({ }^{2} E\right) / \tau\left({ }^{4} T_{2}\right)$ $=30$. Narrow line emission from ${ }^{2} E$ is the dominant feature of the room-temperature PL spectrum from $28 \mathrm{GPa}$. This pressure is needed to increase the ${ }^{2} E-{ }^{4} T_{2}$ energy separation by $E_{\mathrm{ZPL}}\left({ }^{4} T_{2}\right)-E_{\mathrm{ZPL}}\left({ }^{2} E\right)>0.2 \mathrm{eV}$ in order to decrease the ${ }^{4} T_{2}$ emitting state population from ${ }^{2} E$ and compensate effects due to ${ }^{4} T_{2}$ faster transition rate. In contrast, this narrow-line emission is observed just above $6 \mathrm{GPa}$ at low temperature.

The high-pressure Phase II of $\mathrm{LiCaAlF}_{6}$ can be stabilized at ambient conditions after pressure release, improving its laser applications due to enhancement of transition oscillator strength, band broadening, and Stokes shift increase. Phase I is recovered at ambient pressure upon heating $\mathrm{LiCaAlF}_{6}$ phase II above room temperature.

The evolution of the excitation and emission spectra, and the corresponding lifetime are interpreted in terms of pressure-induced ESCO between ${ }^{4} T_{2}$ and ${ }^{2} E$. Both lifetime and PL shift with pressure are explained on the basis of the electron-phonon coupling in ${ }^{4} T_{2}$ and ${ }^{2} E$ states.

The origin of the ${ }^{4} T_{2}+{ }^{2} E+{ }^{2} T_{1}$ resonance was clarified through the knowledge of ${ }^{2} E$ energy from optical spectroscopy at high pressure. We conclude that ${ }^{4} T_{2}+{ }^{2} E$ interact as a Fano resonance whereas ${ }^{4} T_{2}$ and ${ }^{2} T_{1}$ as a Fano antiresonance. This noteworthy result allows us to derive ${ }^{2} E$ and ${ }^{2} T_{1}$ energies directly from the absorption (or excitation) spectrum. 
The crystal-field strength dependence on $R_{\mathrm{Cr}-\mathrm{F}}$ as $\Delta\left(R_{\mathrm{Cr}-\mathrm{F}}\right) \approx K R_{\mathrm{Cr}-\mathrm{F}}^{-n}$, follows a potential law with an exponent $n=3.8$, derived from time-resolved excitation spectra under pressure and the local EOS for $\mathrm{CrF}_{6}^{3-}$. This is significantly lower than the value $n=5$ typically found for transition-metal ions in fluorides and oxides. When comparing $\Delta$ variation with $V^{1 / 3}$ this exponent decreases to $n=2.3$. Such a difference is attributed to the different compressibility of $\mathrm{LiCaAlF}_{6}$ bulk and $\mathrm{CrF}_{6}^{3-}$, the latter eventually reflecting a lattice relaxation effect of the $\mathrm{F}^{-}$octahedron around $\mathrm{Cr}^{3+}$ in order to preserve the local $\mathrm{Cr}-\mathrm{F}$ distance close to $1.85 \AA$.

\section{ACKNOWLEDGMENTS}

Financial support from the Spanish Ministerio de Ciencia e Innovación (Project No. MAT2008-06873-C02-01/MAT) is acknowledged. F.R. and I.H. also wish to offer their thanks for partial support from the Research Intensification program (I3) of the University of Cantabria, and M.N.S.O. thanks the MEC for a FPU grant (Ref. AP-2004-5954). This work has been carried out within the framework of the MALTA Consolider Ingenio 2010 program (Ref. CSD2007-00045).
*Author to whom correspondence should be addressed. FAX: +34 9422014 02; fernando.rodriguez@unican.es

${ }^{1}$ J. F. Dolan, L. A. Kappers, and R. H. Bartram, Phys. Rev. B 33, 7339 (1986).

${ }^{2}$ K. L. Bray, Transition Metal and Rare Earth Compounds, edited by H. Yersin (Springer, Berlin, 2001), Vol. 213, p. 1.

${ }^{3}$ M. Grinberg, Opt. Mater. 19, 37 (2002).

${ }^{4}$ U. Hömmerich and K. L. Bray, Phys. Rev. B 51, 12133 (1995).

${ }^{5}$ A. Kaminska, A. Suchocki, L. Arizmendi, D. Callejo, F. Jaque, and M. Grinberg, Phys. Rev. B 62, 10802 (2000).

${ }^{6}$ S. A. Payne, L. L. Chase, and G. D. Wilke, J. Lumin. 44, 167 (1989).

${ }^{7}$ S. A. Payne, L. L. Chase, H. W. Newkirk, L. K. Smith, and W. F. Krupke, IEEE J. Quantum Electron. 24, 2243 (1988).

${ }^{8}$ L. K. Smith, S. A. Payne, W. L. Kway, L. L. Chase, and B. H. T. Chai, IEEE J. Quantum Electron. 28, 2612 (1992).

${ }^{9}$ I. Hernandez, F. Rodriguez, and A. Tressaud, Inorg. Chem. 47, 10288 (2008).

${ }^{10}$ Y. R. Shen and K. L. Bray, Phys. Rev. B 56, 10882 (1997).

${ }^{11}$ M. Grinberg, J. Barzowska, Y. R. Shen, and K. L. Bray, Phys. Rev. B 63, 214104 (2001).

${ }^{12}$ A. Kaminska, A. Suchocki, S. Kobyakov, L. Arizmendi, M. Potemski, and F. J. Teran, Phys. Rev. B 76, 144117 (2007).

${ }^{13}$ A. Grzechnik, V. Dmitriev, H. P. Weber, J. Y. Gesland, and S. Van Smaalen, J. Phys.: Condens. Matter 16, 1033 (2004).

${ }^{14}$ J. Ferguson, H. J. Guggenheim, and D. L. Wood, J. Chem. Phys. 54, 504 (1971).

${ }^{15}$ P. Greenough and A. G. Paulusz, J. Chem. Phys. 70, 1967 (1979).

${ }^{16}$ R. H. Bartram, J. C. Charpie, L. J. Andrews, and A. Lempicki, Phys. Rev. B 34, 2741 (1986).

${ }^{17}$ H. W. H. Lee, S. A. Payne, and L. L. Chase, Phys. Rev. B 39, 8907 (1989).

${ }^{18}$ S. A. Payne, L. L. Chase, L. K. Smith, W. L. Kway, and H. W. Newkirk, J. Appl. Phys. 66, 1051 (1989).

${ }^{19}$ C. M. De Lucas, F. Rodríguez, J. M. Dance, M. Moreno, and A. Tressaud, J. Lumin. 48-49, 553 (1991).

${ }^{20}$ J. F. Dolan, A. G. Rinzler, L. A. Kappers, and R. H. Bartram, J. Phys. Chem. Solids 53, 905 (1992).

${ }^{21}$ A. M. Woods, R. S. Sinkovits, J. C. Charpie, W. L. Huang, R. H. Bartram, and A. R. Rossi, J. Phys. Chem. Solids 54, 543 (1993).

${ }^{22}$ N. P. Barry, S. C. W. Hyde, R. Mellish, P. M. W. French, J. R. Taylor, C. J. Van Der Poel, and A. Valster, Electron. Lett. 30,
1761 (1994).

${ }^{23}$ P. T. C. Freire, O. Pilla, and V. Lemos, Phys. Rev. B 49, 9232 (1994).

${ }^{24}$ M. M. De Lucas, J. M. Dance, F. Rodriguez, A. Tressaud, M. Moreno, and J. Grannec, Radiat. Eff. Defects Solids 135, 19 (1995).

${ }^{25}$ R. J. M. Da Fonseca, A. D. Tavaresjr, P. S. Silva, T. Abritta, and N. M. Khaidukov, Solid State Commun. 110, 519 (1999).

${ }^{26}$ L. P. Sosman, A. D. Tavares, Jr., R. J. M. Da Fonseca, T. Abritta, and N. M. Khaidukov, Solid State Commun. 114, 661 (2000).

${ }^{27}$ P. A. Tanner, Chem. Phys. Lett. 388, 488 (2004).

${ }^{28}$ M. N. Sanz-Ortiz, F. Rodriguez, I. Hernandez, R. Valiente, and S. Kück, High Press. Res. 26, 345 (2006).

${ }^{29}$ M. A. Illarramendi, J. Fernández, and R. Balda, J. Phys.: Condens. Matter 14, 555 (2002).

${ }^{30}$ M. Voda, J. García Solé, F. Jaque, I. Vergara, A. Kaminskii, B. Mill, and A. Butashin, Phys. Rev. B 49, 3755 (1994).

${ }^{31}$ M. D. Sturge, H. J. Guggenheim, and M. H. L. Pryce, Phys. Rev. B 2, 2459 (1970).

${ }^{32}$ P. Kenyon, L. Andrews, B. Mccollum, and A. Lempicki, IEEE J. Quantum Electron. 18, 1189 (1982).

${ }^{33}$ I. Hernández and F. Rodríguez, Phys. Rev. B 67, 012101 (2003).

${ }^{34}$ I. Hernández, F. Rodríguez, and H. D. Hochheimer, Phys. Rev. Lett. 99, 027403 (2007).

${ }^{35}$ S. Kuze, D. Du Boulay, N. Ishizawa, N. Kodama, M. Yamaga, and B. Henderson, J. Solid State Chem. 177, 3505 (2004).

${ }^{36}$ M. N. Sanz-Ortiz, Graduate thesis (Tesina), Universidad de Cantabria, 2004.

${ }^{37}$ J. S. Griffith, The Theory Of Transition-Metal Ions (Cambridge University Press, Cambridge, 1980).

${ }^{38}$ K. Syassen, High Press. Res. 28, 75 (2008).

${ }^{39}$ G. J. Piermarini, S. Block, J. D. Barnett, and R. A. Forman, J. Appl. Phys. 46, 2774 (1975).

${ }^{40}$ U. Fano, Phys. Rev. 124, 1866 (1961).

${ }^{41}$ L. Ley, R. Kärcher, and R. L. Johnson, Phys. Rev. Lett. 53, 710 (1984).

${ }^{42}$ V. Luana, M. Bermejo, M. Florez, J. M. Recio, and L. Pueyo, J. Chem. Phys. 90, 6409 (1989).

${ }^{43}$ M. Moreno, M. T. Barriuso, and J. A. Aramburu, J. Phys.: Condens. Matter 4, 9481 (1992).

${ }^{44}$ M. G. Brik and K. Ogasawara, Phys. Rev. B 74, 045105 (2006).

${ }^{45}$ M. Grinberg, Opt. Mater. 28, 26 (2006).

${ }^{46}$ M. Grinberg and A. Suchocki, J. Lumin. 125, 97 (2007). 